Authors have nothing to disclose with regard to commercial support.

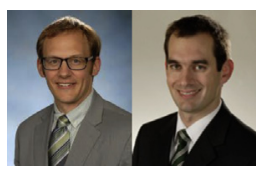

\section{$\beta$-BLOCKERS IN \\ AORTIC VALVE \\ SURGERY: BETA SAFE THAN SORRY?}

\section{To the Editor:}

We recently read with interest the article by Schubert and colleagues ${ }^{1}$ on $\beta$-blocker use in patients undergoing aortic valve replacement surgery. This study is provocative and timely, given the increased emphasis on quality reporting in cardiac surgery and recent uncertainties about perioperative $\beta$-blocker use. In their analysis, Schubert and colleagues ${ }^{1}$ found that patients taking $\beta$-blockers had increased risks of postoperative atrial fibrillation, allogeneic transfusion, and renal failure requiring dialysis. These findings should be interpreted cautiously for several reasons.

First, Schubert and colleagues ${ }^{1}$ analyzed 19 study outcomes, which substantially increases the probability of a false-positive finding. When 20 statistical comparisons are made, the incidence of type 1 error, finding a significant difference that does not actually exist, is $64 \%{ }^{2}$ Considering the study's findings from a Bayesian perspective, it is unlikely that preoperative $\beta$-blocker use actually increases postoperative atrial fibrillation.

Second, Schubert and colleagues ${ }^{1}$ did not have data on $\beta_{1}$ selectivity. Because $\beta$-blockers have diverse pharmacology, categorizing them together almost certainly introduces bias. For example, nebivolol has 40:1 $\beta_{1}$ to $\beta_{2}$ selectivity, whereas carvedilol has $0.6: 1{ }^{3}$ Drugs that have $\beta_{1}$ selectivity are associated with better perioperative outcomes, but they tend to be more expensive and less prescribed. ${ }^{4}$ Alternatively, blockade of $\beta_{2}$ receptors reduces renal blood flow and cerebral oxygen delivery, particularly in the setting of hemodilution. ${ }^{5}$ If a high percentage of patients in the study of Schubert and colleagues ${ }^{1}$ received nonselective $\beta$-blockers, this could explain the study's outcomes; however, it may also limit its generalizability, because $\beta$-blocker prescribing practices change with time.

Finally, the Society of Thoracic Surgeons definition for preoperative $\beta$-blocker use is too narrow to draw

\footnotetext{
The Editor welcomes submissions for possible publication in the Letters to the Editor section that consist of commentary on an article published in the Journal or other relevant issues. Authors should: • Include no more than 500 words of text, three authors, and five references. • Type with double-spacing. • See http://jtcs.ctsnetjournals.org/ misc/ifora.shtml for detailed submission instructions. • Submit the letter electronically via jtcvs.editorialmanager.com. Letters commenting on an article published in the JTCVS will be considered if they are received within 6 weeks of the time the article was published. Authors of the article being commented on will be given an opportunity of offer a timely response ( 2 weeks) to the letter. Authors of letters will be notified that the letter has been received. Unpublished letters cannot be returned.
}

meaningful conclusions from a large, multicenter database. The Society of Thoracic Surgeons defines preoperative $\beta$-blocker use as receiving any $\beta$-blocker within 24 hours of surgery. There is no accounting for whether $\beta$-blocker use was long-standing or initiated just before surgery. This is important, because long-term $\beta$-blocker use is more likely to be beneficial in patients with severe aortic stenosis than a single dose of a $\beta$-blocker given just before surgery.

In summary, the study by Schubert and colleagues ${ }^{1}$ highlights the need for more studies on $\beta$-blockers in cardiac surgery. It has significant limitations, however, which need to be considered before drawing general conclusions about $\beta$-blocker use in patients with aortic stenosis who require aortic valve replacement surgery.

\section{Michael A. Mazzeffi, MD, MPH, $M S c^{a}$ \\ Charles F. Evans, $M D^{b}$ \\ ${ }^{a}$ Department of Anesthesiology \\ University of Maryland School of Medicine \\ Baltimore, $M d$ \\ ${ }^{b}$ Division of Cardiothoracic surgery \\ Department of Surgery \\ University of Maryland School of Medicine \\ Baltimore, $M d$}

\section{References}

1. Schubert SA, Hawkins RB, Mehaffey JH, Chancellor WZ, Fonner CE, Speir AM et al. Preoperative $\beta$-blocker use correlates with worse outcomes in patients undergoing aortic valve replacement. J Thorac Cardiovasc Surg. 2019;158: 1589-97.

2. Althouse AD. Adjust for multiple comparisons? It's not that simple. Ann Thorac Surg. 2016;101:1644-5.

3. Ladage D, Schwinger RH, Brixius K. Cardio-selective beta-blocker: pharmacological evidence and their influence on exercise capacity. Cardiovasc Ther. 2013;31:76-83.

4. Wallace AW, Au S, Cason BA. Perioperative $\beta$-blockade: atenolol is associated with reduced mortality when compared to metoprolol. Anesthesiology. 2011; 114:824-36.

5. Hare GMT, Worrall JMA, Baker AJ, Liu E, Sikich N, Mazer CD. $\beta 2$ adrenergic antagonist inhibits cerebral cortical oxygen delivery after severe haemodilution in rats. Br J Anaesth. 2006;97:617-23.

\section{https://doi.org/10.1016/j.jtcvs.2019.05.060}

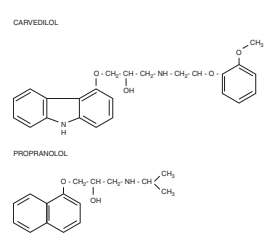

\section{REPLY: DO WE NEED \\ TO BLOCK $\beta$ - BLOCKERS IN AORTIC VALVE \\ REPLACEMENT? \\ Reply to the Editor:}

Preoperative $\beta$-blocker therapy has been used as a quality measure for patients undergoing coronary artery bypass grafting surgery to decrease postoperative mortality and adverse events. In 2013, LaPar and colleagues ${ }^{1}$ questioned the use of $\beta$-blocker as a quality metric, after comparing the early outcomes after coronary 